\title{
Hacia una mayor comprensión del empoderamiento: Las vendedoras ambulantes mixtecas en Tijuana y la participación del Estado Lya Niño Contreras*
}

\section{Resumen}

La migración indígena femenina hacia ciudades del norte de México, sin perder de vista los conflictos presentes del proceso, generalmente es concebida como un sujeto activo en los lugares de destino, donde las relaciones de poder y la resignificación de la cultura en el nuevo contexto desempeñan un papel fundamental. El propósito es analizar las relaciones de poder de las vendedoras ambulantes mixtecas concretamente en el espacio público; para lo anterior, se analiza el caso de interfaz: las mujeres y el Estado. Nos basamos en una concepción de poder fluida, multidireccional y relacional, donde no hay figuras "poderosas" a priori ni externas a las relaciones sociales, y donde el ejercicio del poder implique ejercerlo y cederlo a la vez (Villarreal, 1994, 2000); Así como en una concepción donde el capital social se genere en las relaciones sociales y se negocie. Lo anterior permitirá desmitificar la idea de que el poder y el empoderamiento son lineales y visualizar a las mujeres mixtecas como sujetos capaces de ejercer poder.

Palabras clave: empoderamiento, capital social, vendedoras ambulantes mixtecas, Estado, racismo.

\section{Abstract}

Femenine indigenous migration towards cities located in Northern Mexico, without disregarding the conflicts entailed by the process, is generally conceived as an active subject in the social-cultural construction at the places of destination, where the power relations and the resignification of culture in the new context play a key role. The aim is to analyze the power relations of the Mixtecan Street vendors, specifically and concretely in the public space, for which reason the case of the interface between Women and the State is analyzed herein. The basis for our study resides in the fluid, multidimensional, relational conception of power, where there are no a priori "powerful" figures, nor figures deemed external to social networks; there are also no relationships based on submission. Rather, we see that the exercise of power entails exercising it and relinquishing it at once (Villarreal, 1994, 2000). It is also based on a conception where social capital may be generated in social networks, and is negotiated.

Keywords: empowerment, social capital, Mixtecan street vendors, State, racism.

* Investigadora del Instituto de Investigaciones Sociales de la Universidad Autónoma de Baja California. Correo electrónico: lnino@uabc.edu.mx 


\section{Introducción}

Históricamente las localidades de la frontera norte de México han fungido como áreas de paso o estación para cruzar hacia Estados Unidos. Los grupos indígenas no nativos del estado de Baja California como son los nahuas, mazahuas, purépechas y mixtecos, entre otros, han sido partícipes de esta corriente. En particular, la condiciones que han enfrentado y enfrentan las familias mixtecas que han emigrado y se han asentado en la ciudad de Tijuana se relacionan con distintas situaciones provocadas por los nuevos contextos y retos que significa enfrentar un nuevo escenario familiar donde los hombres del hogar (padre y en algunos casos también los hijos) se separan del núcleo para buscar mejores oportunidades.

En este contexto es que las mujeres indígenas mixtecas llegan a la ciudad de Tijuana en franca desventaja respecto de otros migrantes, siendo las principales causas de esto el analfabetismo, el monolingüismo y las pocas habilidades para manejarse en el medio urbano (Clark, 1996), donde además está presente una serie de obstáculos que inhiben y/o dificultan el proceso; es así que a poco más de tres décadas de su llegada a la ciudad han modificado sus condiciones materiales de vida y sus relaciones de poder (Niño, 2009).

El objetivo del presente documento es analizar las relaciones de poder de las vendedoras ambulantes mixtecas asentadas en la ciudad de Tijuana, concretamente en el espacio público. Para esto se analiza el caso de interfaz: las vendedoras ambulantes mixtecas y el Estado.

Nos apoyamos en la concepción de poder de Villarreal quien nos dice que:

[...] el poder existe en el grado en el que es ejercido sobre otros, y por lo tanto, en el grado en que se presentan fuerzas contestatarias que deben ser controladas. Usualmente implica sólo el logro parcial de la voluntad de un agente dado que está basado en la negociación, donde el ejercicio del poder presupone el ejercicio de cederlo. Las principales características de este poder son: su naturaleza fluida, por lo tanto, no es acumulable, no es inherente a ninguna posición o persona, su no intencionalidad y la multidireccionalidad (Villarreal, 1994, 2000). 
Así como en las consideraciones respecto de la naturaleza del poder que hace la misma autora: la primera concierne a la cuestión de intencionalidad; la segunda es que el poder no es inherente a una posición, un espacio o una persona; y la tercera se refiere a la multidireccionalidad de las relaciones de poder (puntos que ampliaremos posteriormente).

De igual forma nos basamos en el enfoque orientado al actor y el análisis de la interfaz social (Long, 2001), mismos que consideramos pertinentes por su dinamismo en el sentido de que permiten observar el inter-juego y la mutua determinación de factores y relaciones "internas" y "externas". Lo cual se logra a partir de tomar en cuenta seriamente la agencia humana y en conceder importancia analítica a los procesos de construcción y reproducción del tejido social (Long, en Villarreal, s/f).

Long (en Villarreal, 2000) define las interfaces como los puntos críticos de intersección entre diferentes sistemas sociales, campos, dominios o niveles de orden social donde es más probable que se localicen discontinuidades basadas en discrepancias de valores, intereses, conocimiento y poder. Tales discontinuidades caracterizan las situaciones sociales donde las interacciones entre actores se orientan al problema de diseñar maneras de puentear, acomodarse a, o luchar contra los mundos sociales y cognitivos de uno y otro.

Continuando con Villarreal, el análisis de las interfaces sociales se puede aplicar de manera fructífera para entender los procesos de intervención planeada por parte del Estado u organismos no gubernamentales o políticos pues aporta ángulos de observación valiosos al estudio de los movimientos sociales. Puede ser útil también en el estudio de procesos migratorios, de relaciones de poder y de desigualdades de género, entre muchos otros campos de análisis. De igual forma, Villarreal (s/f) nos dice que la exploración de interfaces requiere de herramientas metodológicas cruzadas. Este artículo es producto de una investigación más amplia y cuenta con una buena dosis de investigación etnográfica lo cual permitió la convivencia y el conocimiento de las rutinas cotidianas de las mujeres en cuestión. También se realizaron entrevistas a diez vendedoras mixtecas ambulantes en Tijuana, a funcionarios gubernamentales como el jefe de la policía de Tijuana, el jefe de la zona centro de Tijuana, a las hermanas Martha y Fernanda de la organización no gubernamental Príncipe de Paz. Todo lo anterior permitió aproximarnos a los mundos de vida de las mu- 
jeres, de sus relaciones sociales y de poder en el espacio público. El trabajo de campo se realizó en el periodo 2003-2005 con visitas esporádicas posteriores hasta los años 2007 y 2008.

El presente trabajo se divide en cuatro apartados: el primero de ellos corresponde al sustento teórico y contiene información sobre la concepción del empoderamiento, del poder, del capital social, la identidad de género, la identidad étnica, las mujeres indígenas, la migración y las mujeres indígenas en Tijuana. En el segundo apartado se expone el caso de interfaz social: las vendedoras ambulantes mixtecas en Tijuana y el Estado, el cual se presenta en dos escenarios: la antesala de la oficina del jefe de Reglamentos de la zona centro y la oficina del jefe de Reglamentos de la zona centro. El tercero comprende el análisis de la interfaz social a partir de la concepción de poder de Villarreal y sus tres consideraciones en torno al poder; y en el cuarto y último apartado aparecen las reflexiones finales.

\section{Sustento teórico}

Para una mayor comprensión de las relaciones de poder de las mujeres vendedoras ambulantes mixtecas es imprescindible contar con una serie de antecedentes y elementos teóricos. El presente apartado contiene información en torno al empoderamiento, poder, capital social, identidad de género, identidad étnica, mujeres indígenas, migración y mujeres indígenas en Tijuana. Sin embargo, por cuestiones de espacio se presenta en forma abreviada.

Empoderamiento: La aplicación del término al estudio de las relaciones que establecen las mujeres en su vida cotidiana es reciente, aunque desde tiempo atrás se han realizado diversos estudios que de forma explícita o implícita hacen referencia a los roles que se atribuyen a las mujeres en la sociedad, así como a las relaciones de poder entre los distintos géneros. El empoderamiento es un concepto polémico, entre sus antecedentes se encuentra el movimiento popular de los derechos civiles en Estados Unidos, surgido en los años de la década de 1960. En dicho movimiento la población de origen afroamericano que tenía por objetivo la lucha por los derechos civiles hizo un llamado al "poder negro", el cual definieron 
como "un llamado para que la gente negra en este país sea una, reconozca su herencia y construya su sentido de comunidad. Es un llamado para que la gente comience a definir sus propias metas, a vincularse y apoyar a sus propias organizaciones" (León, 1997:76).

No fue sino hasta mediados de la década de 1970 que el empoderamiento comenzó a ser aplicado en los movimientos de las mujeres. Su uso probablemente se internacionalizó con la obra de Sen y Grown titulada Desarrollo, crisis y enfoques alternativos: perspectivas de las mujeres en el tercer mundo (Stromquist, 1997:77). El uso del concepto varía de acuerdo con la disciplina que lo utiliza: la psicología, la antropología, la ciencia política, la educación, el derecho y la economía. Los agentes que lo usan son disímiles. En la amplia gama de usuarios se encuentran los organismos internacionales, los agentes del Estado, los académicos, los patronos, los empresarios, los activistas sociales, los grupos de desarrollo comunitario, los grupos alternativos y las mujeres en sus varias posiciones.

Aunque han sido los estudios de la mujer y género, y particularmente en el campo de la mujer en el desarrollo, los que han utilizado el concepto como uno de los ejes del discurso, no existe consenso en cuanto a su sentido.

Por ejemplo, para Batliwala (1993) el empoderamiento implica dos aspectos centrales: control sobre los recursos (físicos, humanos, intelectuales, financieros, y el de su propio ser) y control sobre la ideología (creencias, valores y actitudes).

Poder y empoderamiento: El mainstream del empoderamiento se apoya en una de las formas más comunes y generales de entender el poder en las ciencias sociales, entre éstas se encuentran las de Dahl (1957) y Weber (1946:152); este último define el poder como "la probabilidad que un actor en una relación social esté en la posición de llevar a cabo sus deseos a pesar de la resistencia, independientemente de la base sobre la cual probablemente descansa". Es decir, que $A$ lleve a cabo las intenciones o deseos de $B$. ¿Pero podemos hablar de ganadores y perdedores? Es decir, ¿̇e trata de un proceso de suma cero? Así, se reconoce una cualidad de suma cero al poder, lo cual contrasta con lo que encontramos en la vida cotidiana. Lo que significaría asumir y pensar que el empoderamiento de las mujeres llevaría a un "desempoderamiento" de los hombres. Encontramos esta concepción problemática en el sentido de que se percibe a las mujeres 
como víctimas o con escaso poder, además de dejar la impresión de que el empoderamiento es algo externo a las relaciones sociales de las mismas. Sin embargo, la concepción tradicional de poder ha sido cuestionada y retrabajada por autores como Foucault (1984), Latour (1986) y Villarreal (1994, 2000). Para efectos de este trabajo nos inclinamos por la concepción de Villarreal (2000:21) acerca de que "el poder existe en el grado en el que es ejercido sobre otros, y por lo tanto, en el grado en que se presentan fuerzas contestatarias que deben ser controladas. Usualmente implica sólo el logro parcial de la voluntad de un agente dado que está basado en la negociación, donde el ejercicio del poder presupone el ejercicio de cederlo”. Asimismo, Villarreal (2000:18) señala tres consideraciones en torno a la naturaleza del poder: primero, la cuestión de intencionalidad; segundo, el poder no es inherente a una posición, un espacio o una persona; y finalmente, la multidireccionalidad de las relaciones de poder (puntos que ampliaremos posteriormente).

Género y empoderamiento: Desde las perspectivas mainstream en torno al empoderamiento, una vez que las mujeres sean concientes de su situación de opresión y se capaciten, se empoderarán de forma continua. La identidad de género tiene un papel importante en la configuración de sistemas binarios que establecen o delimitan espacios para cada uno de los géneros a partir de una construcción simbólica establecida sobre los datos biológicos que toman forma a partir de las matrices culturales y sociales en las que están insertos (Conway, 1987).

En términos muy generales esto ha implicado que al hombre se le asocie a la capacidad para el trabajo instrumental (público-productivogerencial) y a la mujer como complemento en su habilidad para manejar los espacios expresivos de la vida familiar y la crianza. Al respecto, Gayle (1997) hace referencia a la dimensión de desigualdad que cobra forma a partir de la diferencia, de lo que Ortner y Whitehead (1997) resaltan la importancia del prestigio asociado al género masculino. Scott (1997) nos dice que sin importar el periodo histórico, los sistemas de género son binarios, donde el hombre y la mujer son oponentes así como lo masculino y lo femenino, por lo general, en un orden jerárquico y no en un plano de igualdad.

Al referirse a la identidad de género, Lamas (1986) explica que ésta se establece más o menos a la edad en que el infante adquiere el lenguaje 
(entre los dos y los tres años) y que una vez establecida se convierte en un tamiz por el que pasan todas sus experiencias (Lamas, 1986:113).

Estamos de acuerdo con estas posturas, pero sólo hasta cierto punto. Consideramos conveniente citar a Conway (1986:24), quien enfatiza que las fronteras de género, al igual que las de clase, se trazan para servir a una gran variedad de funciones políticas, económicas y sociales. Estas fronteras son a menudo móviles y negociables. Operan no sólo en la base material de la cultura sino en el mundo imaginario del artista creativo.

Capital social: Hace referencia a los recursos sociales disponibles y capaces de brindar al actor y grupos particulares una serie de beneficios. El capital social se ha considerado como un recurso estandarizado, como externo a las relaciones sociales y equiparado al capital económico, susceptible de acumularse y producir beneficios económicos. Por ejemplo, Portes (1998) hace una analogía entre los recursos sociales y los chips o bauchers guardados en el bolsillo del pantalón, o favores realizados prestos a reclamarse en el instante.

Aspectos que encontramos problemáticos. Al respecto, Villarreal (2001) nos dice que el capital social "es un recurso específico, sea o no monetario, que sólo puede convertirse en capital cuando entra en circulación dentro de circuitos particulares de significado en los cuales se cotiza y negocia su valor de acuerdo con ciertas normas, expectativas y estándares". Lo anterior implica que el capital social no es a priori o externo a las relaciones sociales, ni recursos en sí mismos, sino que éstos se generan en las relaciones sociales y se negocian, lo cual representa un llamado de atención a quienes alarmados por la pérdida de reservas de capital proponen inyectarlo.

Asimismo, Villarreal asevera que no es tanto la cantidad de recursos ni la acumulación, sino la movilización, la significación para utilizarse como activo, donde los beneficios no necesariamente son económicos. Al respecto, la identidad puede fungir como elemento "canjeable". Algunas de las mujeres han hecho de la identidad un recurso intangible, mismo que ha resultado ser crucial en diversos contextos, como se verá posteriormente en el análisis de la interfaz social.

Identidad étnica: Es una concepción que no podía faltar en el andamiaje teórico de este trabajo. Al respecto, John y Jean Comaroff (1992) destacan las complejas interrelaciones de la extrema polarización so- 
cioeconómica y la etnicidad en las sociedades latinoamericanas. Por lo que sostienen que la etnicidad se constituye por una incorporación asimétrica de grupos culturalmente diferentes dentro de economías políticas singulares.

A manera de ilustrar la asimetría de poder implícita en las relaciones del indígena con el mestizo, así como algunas de las formas de racismo que se describen en este trabajo, retomamos el estudio de Camus (2000) en el que se documenta la agreste recepción que tiene el indio en la ciudad así como las denominaciones despectivas y estereotipadoras con que se les señala en diversas ciudades de América Latina, las cuales contienen todas ellas una connotación étnico-racista: "En la ciudad de La Paz, Bolivia, al indio se le conoce como el cholo; en Quito, Ecuador, como longos; en Lima, Perú, como cholo anfibio; en la ciudad de Guatemala, como indio lamido, indio igualado; en la ciudad de México como chichimecos, nacos y totonacos (Camus, 2000:88). Al agregar la condición étnica, las relaciones asimétricas de poder se recrudecen. Al respecto, Lamas (1986), en su análisis de la articulación entre el sistema de prestigio y género, pone en evidencia una importante contradicción. Así, nos dice:

Aunque la estructura de la sociedad sea patriarcal y las mujeres estén subordinadas, los hombres y las mujeres de un mismo rango están mucho más cerca entre sí que de los hombres y las mujeres con otro estatus. La condición universal de subordinación femenina, la diferencia específica de clase (y también de etnia) crea una separación entre las mujeres.

El debate sobre la imposibilidad de desarrollar una propuesta que concilie la igualdad de los problemas de género con las diferencias específicas de clase y etnia, ha sido una constante (Hernández, 2001:206).

De igual forma que a las mujeres en general se les adscriben rolesguiones, lo mismo sucede con las mujeres rurales e indígenas. Por ejemplo, en el caso de las mujeres campesinas, Villarreal (2000) afirma que son tres las imágenes que representan típicamente a la mujer campesina en México: la ama de casa atada al comal y al metate; la madre y esposa sumisa; y la trabajadora del campo laborando bajo los rayos del sol. A estas imágenes se asocian otras como las de marginación, analfabetismo, ignorancia, falta de productividad, pobreza, desnutrición y desaseo. No 
hay que perder de vista que si los guiones de género están mediados por relaciones desiguales, en el caso de las mujeres indígenas esto se acentúa de manera importante, pues durante la "Conquista" la diversidad racial y cultural se convirtió en razón ideológica para justificar el dominio y la explotación. Además, los roles o guiones de género de las mujeres indígenas se ven permeados por el racismo (Taguieff, 2001:9). Esto es, que la actual configuración de la etnicidad proviene de un proceso iniciado tras la colonización, el cual se distribuye en sus múltiples dimensiones:

a) Las actitudes en las que operan (opiniones, creencias, prejuicios, estereotipos). Es el racismo de "doxa" que se manifiesta por diversos modos de estigmatización (injurias, insultos, llamados al odio, amenazas, etcétera).

b) Los comportamientos o las prácticas sociales del evitamiento a la discriminación y a la persecución, ligados o no a las movilizaciones de masas; los funcionarios institucionales de tipo excluyente ("el racismo institucional”); los discursos ideológicos, ligados o no a programas políticos.

Asimismo, nos dice el autor, el racismo no se manifiesta en su estado puro, sino como un componente de configuraciones ideológicas donde se conjuga con otros "ismos": nacionalismo, colonialismo, eugenismo, socialdarwinismo, etcétera. Las construcciones o las interpretaciones históricas de los "otros" "racializados".

En este caso, al indio, como señala Braunstein (2001), se le atribuyen no las virtudes sino los defectos: perezoso, sucio, indolente, tonto, miserable, feo, ladino, traidor. Lo anterior nos remite a la situación del indígena en la ciudad de Tijuana. Turísticamente hablando se le atribuyen virtudes a nuestros orígenes. Es así que a lo largo de las áreas más turísticas de la ciudad encontramos figuras representando las culturas prehispánicas. Pero cuando esos "objetos" inanimados cobran vida y se materializan en las mujeres mixtecas que desempeñan la venta ambulante o se enfrentan con las autoridades demandado el respeto a sus derechos, empiezan los problemas.

Respecto de los indígenas, nos dice Braunstein (2001), son vistos como salvajes, bárbaros, "primitivos", "menos evolucionados" о "poco evolucio- 
nados", imperfectibles, incivilizados o degenerados y otros portadores de "taras" o de defectos supuestamente hereditarios: los biológica o genéticamente inferiores, los "inadmisibles", los "indeseables", tal como llama el jefe de Reglamentos a las mujeres mixtecas en cuestión, como se verá posteriormente. ¿Pero qué sucede en relación con las mujeres indígenas? Al respecto, traemos a colación el caso de las mujeres indias en Chiapas. Diversas autoras han señalado que éstas han sido siempre violadas por los ladinos (Arizpe, 1988; Hernández, 1999; Van de Berghe, 1971; Favre, 1992; Guillén, 1994; París Pombo, en Gall, 2001:107); asimismo, Gall señala que los miembros de los Altos no han hecho sino reiterar su convicción de que las mujeres indias son el elemento más despreciable de este grupo "débil mental y pueril" y que, por lo tanto, la violencia resultante de este desprecio es legítima. Ahora veamos qué sucede cuando se entrecruzan las categorías de género, etnicidad y migración en general y en particular en la ciudad de Tijuana.

Mujeres indígenas y migración: Hasta los años ochenta podríamos decir que son pocos los estudios en torno a la experiencia migratoria de la mujer. Al respecto, diversos autores (Woo, 2001; Velasco, 1995, 2000; Ariza, 2000a, 2000b; Oehmichen, 2000; Szasz, 1994) han documentado que en los estudios de migración la mujer es considerada sólo como una acompañante, por lo que fue prácticamente invisible su presencia. Y más escasos aún son los que abordan la problemática de las mujeres indígenas, particularmente los que se enfocan en ella no sólo como una acompañante, sino en su calidad de actor social.

Un estudio pionero en torno a la migración indígena es el de Arizpe (1975). En éste se aborda la presencia de las mujeres en la ciudad de México y se discute la cuestión de la incorporación de la cultura indígena a la mestiza. Pero como bien señala Martínez (2007), es a la luz de un mayor desarrollo teórico de experiencia etnográfica e incorporación de la categoría del género, que surgen algunos estudios que critican las posturas que presuponían que la asimilación, la aculturación y la proletarización eran la única opción de los migrantes pobres en la ciudad.

Al hablar de la coexistencia de las categorías indígena y migrante nos interesa destacar que algunos autores y autoras consideran que agregar la categoría o condición étnica a la de clase y género, implica hablar de una triple opresión (Lagarde, 1996; Canabal, 1997), y si a éstas le agregamos la de migrante, la situación de vulnerabilidad de las mujeres se recrudece 
(Morokvásic, 1983). Sin embargo, hay una gran cantidad de trabajos que nos apoyan como marco general en la comprensión de cómo se ha entendido la situación de poder de las mujeres, aunque muchos de ellos se han centrado principalmente en mujeres rurales, extrapolando los resultados a la población indígena en general, subsumiendo así la experiencia o categoría étnica a lo rural, por lo que es conveniente enfocarnos en la población indígena y en particular en las mujeres migrantes.

Es así que otros autores, sin soslayar los conflictos presentes en el proceso migratorio de las mujeres indígenas (tales como la situación de desigualdad que se materializa en un alto índice de monolingüismo, analfabetismo y discriminación), conciben a la población indígena migrante como sujetos activos en la construcción social-cultural en los lugares de destino, donde la resignificación de la cultura indígena en el nuevo contexto, sea urbano o rural, desempeña un papel importante (Velasco, 1995, 2000; Oehmichen, 2000; Camus, 2000; Bastos, 2000). Además de identificar una continuidad o reproducción de los patrones culturales propios en su lugar de origen, estos autores también identifican cambios.

En su estudio sobre migración mazahua a la ciudad de México, Oehmichen (2000:340) encuentra que las redes sociales centradas en la madre y las relaciones de parentesco por vía materna adquieren una nueva importancia en la ciudad y en el desempeño de la venta ambulante. Al respecto, señala la autora que si en la comunidad estas mujeres se encontraban más distantes debido a diferentes adscripciones socioterritoriales que adquieren en tanto esposas, en el medio urbano y en el desempeño de la venta ambulante, los contactos entre ellas tienden a ser más frecuentes.

El uso de la lengua y el vestido adquiere una nueva funcionalidad en la ciudad. La opción de vestir el traje típico de acuerdo con la situación ha sido señalada como una práctica "camaleónica” por los indígenas guatemaltecos emigrantes a las ciudades y que en algunos de los casos es importante para el logro de la movilidad social En cambio, Camus (2000) encuentra que el vestido puede tener el sentido de una estrategia política. En este último punto coinciden los estudios sobre las mujeres mazahuas dedicadas a la venta ambulante en la ciudad de México (Oehmichen, 2000) y las otomíes en Guadalajara (Martínez, 2007).

Otro de los cambios es el referente al papel de la mujer como figura o motor económico de la familia a partir de su práctica en la venta ambulan- 
te en las ciudades de Guadalajara y México, misma que realizan conjuntamente con las hijas (Martínez, 2007; Oehmichen, 2000).

Destaca también la noción de cruces de fronteras, donde en algunos casos ésta está implícita y en otros se hace de manera explícita, como en Oehmichen (2000), quien habla del cruce de fronteras geográficas y simbólicas, incluyendo, por ejemplo, el arreglo personal (como el uso de maquillaje); mientras que Camus los identifica con los cambios y la innovación en el diseño del vestido. También destacan las condiciones de desempleo y subempleo que padecen u operan como un elemento que corre en contra del cumplimiento de las obligaciones y responsabilidades atribuidas a las masculinidades "legítimas" (Oehmichen, 2000; Martínez, 2007). Lo anterior tiene que ver con los guiones de género y en este caso se esperaría que el hombre fuera el proveedor. Llama la atención de manera especial el flujo de información sobre derechos internacionales de los grupos indígenas a las ciudades capitales (Camus, 2000; Oehmichen, 2000).

Sin embargo, un aspecto que se señala reiteradamente como poco cambiante es el referente a las relaciones de género. Continúan reproduciéndose las jerarquías varoniles, la identificación de las actividades del hombre con la esfera de lo público y su consecuente valoración en detrimento de la mujer, a quien se asocia a la esfera de lo privado y lo trivial. Citamos el estudio de Anguiano (1997) quien documenta la migración mixteca al estado de Nuevo León. En este estudio el autor encuentra que mientras los varones han aprendido el español y han ido a la escuela, no sucede así con las mujeres, pues en la comunidad se tiene la percepción de que la educación y el bilingüismo es para los hombres que son los que se tienen que desempeñarse en la calle y no para las mujeres que deben permanecer en casa.

Aun así, otros estudios han identificado cambios en lo referente a la organización social indígena; en la resignificación y cambios en las redes sociales; en la lengua y el vestido que adquieren una nueva funcionalidad; en la importancia del papel económico de la mujer; en el cruce de fronteras; en el desempleo, principalmente de los hombres; así como cambios en el flujo de información. Martínez (2007), por ejemplo, identifica algunos cambios en la organización social indígena de los otomíes migrantes a la ciudad de Guadalajara. Es en la ciudad donde surge la figura del celador, personaje que tiene como objetivo primordial el apoyo a la comunidad migrante, en especial respecto de la reproducción cultural. Por ejemplo, se encarga de vincular a los 
migrantes con la comunidad de origen, además de operar como mecanismo de control, pues también vigila el comportamiento de los migrantes.

La autora asocia este tipo de organización con el sentido holista del grupo, lo cual ha sido identificado como una característica de los grupos indígenas (Martínez y De la Peña, 2004). El sentido holista del grupo se materializa en la práctica como una prioridad del grupo sobre el individuo. "El corporativismo u holismo, suelen presentarse como una estrategia pragmática ante la exclusión a la que son sometidos por el mundo urbano. Ya que se ven fuertemente sujetos a procesos de discriminación racista y exclusión por parte de sus vecinos no-indígenas (criollos y mestizos)" (Martínez y De la Peña, 2004:243).

Las mujeres indígenas en Tijuana: En las últimas décadas el flujo migratorio indígena con destino a la frontera de México se ha incrementado de manera constante; en el estado de Baja California, por ejemplo, la población que habla alguna lengua indígena aumentó en 43.13\% desde 1990 al año 2000, y en el municipio de Tijuana desde 1980 se registra poco más de la tercera parte de este sector (INEGI, 1980 y 2000). Si bien se sabe que la población indígena en Tijuana se ha incrementado, a la fecha no se conoce con exactitud a cuánto asciende el total debido a que son escasos los registros actualizados sobre este grupo de población ya que las cifras que se manejan por distintas dependencias varían entre una fuente y otra. De acuerdo con los resultados del Censo de Población y Vivienda realizado en el año 2010 por el Instituto Nacional de Economía, Geografía e Informática (INEGI), el municipio de Tijuana contaba con 11985 personas que hablan alguna lengua indígena de entre cinco años y más, esto de un total de 41005 que habitan en la Baja California (INEGI, 2010).

La presencia indígena femenina en la ciudad de Tijuana data de finales de los años de la década de 1970. Este grupo de mujeres encontró un nicho económico en el sector turístico. Lo anterior ha sido documentado por Velasco (1995) quien señala que en la colonia Obrera, sector de mayor concentración de población indígena en la década de los ochenta, $75 \%$ de las mujeres mixtecas que trabajaba fuera del hogar lo hacía en la venta ambulante, $11 \%$ en el servicio doméstico y $14 \%$ lo hacía en otras actividades.

Actualmente, una gran cantidad de ellas es bilingüe y cuenta con casa propia y permiso para realizar la venta ambulante. Sin embargo, lo an- 
terior no fue sencillo: Velasco (1996) documenta que fueron más de 20 años de lucha para conseguir los permisos, periodo en el que las mujeres enfrentaron la violencia y la represión de sus esposos y de las autoridades municipales, las cuales a toda costa querían impedir su presencia pues "afeaban" las áreas turísticas de la ciudad; sin embargo, finalmente lograron negociar permisos sujetos a renovación anual.

Por otro lado, Velasco documenta que el asentamiento en la ciudad de Tijuana se caracterizó desde su inicio por ser éste el lugar donde se quedaban los familiares de aquellos que se iban a trabajar a Estados Unidos. De esta manera, dicha ciudad se convirtió en uno de los centros urbanos con mayor flujo migratorio indígena en la frontera.

En Tijuana, por otro lado, las mujeres indígenas de la ciudad encontraron un nicho en una de las "vocaciones" económicas del lugar: el turismo. En los estudios sobre la migración indígena a la ciudad de Tijuana destaca la persistencia de relaciones desiguales de poder entre las mujeres y los hombres. Por ejemplo, Velasco (2000) señala las limitaciones en la participación de las mujeres al no contar con el consentimiento de su pareja para participar en las organizaciones políticas que luchan por los derechos de los indígenas. Por otro lado, Lestage (1999) identifica cierta continuidad en el sentido de que siguen reproduciéndose prácticas culturales como el matrimonio endogámico en las comunidades y la venta de la novia, y Clark (1996) señala que a pesar de que las mujeres mixtecas migrantes a Tijuana cuentan con un ingreso económico, éste no les ha dado una mayor independencia frente a su familia debido a la rigidez de la estructura patriarcal. Se entiende por estructura patriarcal una "organización sistemática donde se establece la supremacía del varón y la subordinación de la mujer [...] los primeros oprimen a las segundas por mecanismos directos o indirectos" (Frías, 2007). Regresamos con Clark (1996) quien también enfatiza la condición de desigualdad social de las mujeres y la discriminación de la que son objeto. Sin embargo, el autor encuentra que no siempre hay continuidad en los diferentes ámbitos de la vida, como suele pensarse.

Sin embargo, no todo se reduce a lastres en la vida de las mujeres, y diversos autores han documentado una serie de cambios en éstas. Por ejemplo, Clark (1996) menciona que las vendedoras ambulantes mixtecas han desarrollado sus propias estrategias de venta y agregado a su vocabulario palabras en inglés, indispensables para señalar precios o pedir limosna, y 
que las ganancias de las mujeres indígenas son más altas comparadas con el salario mínimo de la zona; además de que a nivel individual presentan una mayor desinhibición con extraños, usan una vestimenta diferente (pantalón con falda sobrepuesta) y su alimentación ha mejorado así como sus condiciones de vida en términos materiales. Otro aspecto importante que plantea esta investigación es el hecho de que muchas de estas mujeres se convierten en "evasoras de la ley" ya que ejercen la venta sin permiso de las autoridades municipales.

Los cambios en los patrones migratorios y en las prácticas culturales también son señalados por otros autores. Velasco (1995), por ejemplo, reconstruye la ruta migratoria de las mujeres indígenas que se dirigen a la frontera norte de México, en especial la que siguen las mujeres a su llegada y asentamiento en la ciudad de Tijuana; asimismo, identifica la existencia de un patrón reciente de migración directa hacia diferentes lugares del norte del país. Señala la autora que quizá lo anterior está relacionado con un desdibujamiento del patrón holista.

Un cambio que nos concierne de manera particular en este estudio es el señalado por Velasco $(1995,1996)$, quien encuentra logros en términos de poder al documentar la experiencia de la lucha-gestión de las mujeres indígenas para obtener los permisos para la venta; además recupera los testimonios de algunas líderes que participaron en esta lucha. Apoyada en la geografía humana, señala los cruces de frontera donde las mujeres han resistido y luchado por más de 20 años hasta lograr negociar los permisos con las autoridades, con los esposos en casa o con los representantes de gobierno en la administración pública. Asimismo, en ese mismo estudio la autora identifica una multiplicidad de espacios en el propio tránsito de los actores a través de las fronteras entre estos espacios.

Las mujeres han logrado además que se creen guarderías y una escuela primaria bilingüe para sus hijos. La autora señala que se han generado procesos de comprensión y reflexión constante, llevando a una valoración diferente de sí mismas. Además las mujeres lograron movilizar una serie de recursos en su acción colectiva, aumentando su capacidad de resistencia. El uso de la identidad indígena aumenta su capacidad de negociación con el exterior y lleva a una mayor cohesión social del grupo. De esta manera, la autora encuentra un tránsito de las relaciones de subordinación a unas de poder. 


\section{Caso de interfaz social: las vendedoras ambulantes mixtecas en Tijuana y el Estado}

Lunes 4 de agosto

Molestas por las consecuencias del dispositivo llevado a cabo durante el fin de semana, las vendedoras ambulantes se reunieron a temprana hora del lunes con su líder. Nombraron una comisión para ir a protestar ante el jefe de Reglamentos, así como para gestionar la disolución de las infracciones. La comisión quedó integrada por Leobarda, líder general del grupo quien fue acompañada por su pequeña nieta; también iba Rosa, quien representaba a las vendedoras de la línea, Nicolasa y Petra por parte de las vendedoras del puente y quien esto escribe como observadora.

\section{Primer escenario: antesala de la oficina del jefe de Reglamentos}

Camino al edificio donde se encuentran las oficinas del agente de Reglamentos había una carreta de frutas que había sido confiscada y de la que emanaba un olor fétido; una de ellas señaló en mixteco algo que no entendí, y una voz de varón dijo en español "ya te entendí, huele mal”, y a manera de reclamo ella replicó en español: “¿para qué se lo quitan a la gente?".

Al llegar a la oficina, Leobarda empujó la puerta que estaba entreabierta, pero alguien desde adentro la cerró. Desconcertada, Leobarda empujó con fuerza y replicó diciendo: “Traigo gente, ¿̇por qué me cierras?”. Desde adentro una voz de varón respondió: “iSerá por indeseable!”.

Entonces abrieron la puerta, al tiempo que se dejó oír una carcajada de varón en tono burlón. Entramos a las oficinas y de forma contigua a la puerta de entrada había una larga barra o buró para atención al público, dividiendo, no sólo física sino también simbólicamente, el espacio entre el público y los dependientes. A lado derecho se enfilaban los cubículos y escritorios donde había algunos dependientes. Del otro lado había una pequeña antesala. Una vez sentadas en la sala de espera, la barra adquirió otra dimensión: ya no sólo dividía el espacio sino obstaculizaba la vista hacia las oficinas. Nadie se acercaba a preguntarnos qué deseábamos, qué se 
nos ofrecía. En la misma sala de espera, el jefe de Reglamentos atendía a un señor joven, mestizo, de tez blanca. En ese instante, el encargado tomó el teléfono e hizo una llamada pidiendo que se atendiera a un señor que pronto estaría por allá solicitando una identificación para tramitar su visa.

Aparentemente le respondieron que ya no había credenciales, pues éste propuso que se le extendiera una carta. Después de un par de minutos, el jefe de Reglamentos colgó el teléfono y se dirigió al señor comerciante. De manera amable le dijo: "No hay ningún problema, puede pasar a recoger su carta”. El comerciante le agradeció la atención prestada a su petición y se retiró. El jefe de Reglamentos se dispuso entonces a instalar la chapa de la puerta de entrada de la oficina, que estaba ubicada al costado de la sala de espera, a un lado de nosotros, pero aun así evitó el contacto visual. Desenvolvió un manual y se puso a leerlo. La señora Leobarda le reclamó, pidiendo que nos atendiera. El personaje en cuestión nos aplicó la "ley del hielo", incluso siguió sin inmutarse ante nuestra presencia. Fingió no escucharnos. Leobarda insistió y le recomendó llamar a un cerrajero, pero él continuó ignorándonos. La reacción de las mujeres ante los hechos fue conversar en mixteco en voz alta, subir la voz en forma exagerada y carcajearse.

En cuestión de segundos le dieron un giro a la atmósfera. Pareció como si nos hubiéramos trasladado de la oficina del agente de Reglamentos a una tertulia en algún lugar de la mixteca. Entonces él preguntó: “¿De qué están hablando, qué están diciendo en su dialecto?”, pero en esta ocasión ellas simularon no escucharlo y continuaron riendo. Apoyado en el manual, él continuó instalando la chapa. Luego con sorpresa exclamó: “iAlgo salió mal!, la puse al revés”. Entonces, Leobarda dijo: "Te lo dije”, y las mujeres empezaron a reírse a carcajadas de él.

\section{Segundo escenario: oficina del jefe de Reglamentos de la zona centro en Tijuana}

Ante la privacidad de su cubículo donde sólo mediaba un escritorio entre él y nosotras, el jefe de Reglamentos cambió su actitud y recurrió a una estrategia más agresiva. Ahora el contacto visual era directo. Posó la mirada en las de las mujeres, principalmente en la de Leobarda, como una forma de reconoci- 
miento a su autoridad. El agente de Reglamentos estaba de muy mal humor, daba la impresión de que tenía la intención de penetrar la mente de Leobarda y moldear sus deseos y pensamientos. Sin embargo, ni Leobarda ni las otras mujeres mostraron una actitud de víctimas. Leobarda le respondió en la misma frecuencia, con miradas, gestos y preguntas demandantes de respuestas inmediatas tales como "quiero saber si se va a respetar lo de los horarios de dos a cuatro para poder salir". En ese momento él señaló a Nicolasa y dijo: "A ella la multaron porque no estaba en el puesto a esa hora". Nicolasa explicó que tuvo que salir de emergencia y sacó de su bolso la infracción.

Leobarda debía haberla firmado, pero aún no lo había hecho. El jefe le pidió el documento, leyendo en voz alta el monto de la multa: "65 salarios mínimos"; "2.5”, lo corrigió inmediatamente Leobarda. “iBien que sabes!”, contestó el funcionario, instruyendo a Nicolasa que fuera con el juez para que le cancelara la infracción. Tras este altercado, en el que el jefe de Reglamentos pudo percatarse de la "fuerza" de la dirigente, la atmósfera dio un giro. El funcionario empezó a emitir bostezos, mostrando una mezcla de enfado y exasperación.

Finalmente, las mujeres lograron negociar con el jefe de Reglamentos la continuidad de un horario flexible en la atención del puesto de venta y la cancelación de las multas. Pero cuando intentaron negociar un espacio para las trenzeras, éste estalló gritando que esto no era posible y no sabía lo que estaba pasando con el centro de la ciudad, el cual estaba infestado de trenzeras.

\section{Análisis de la interfaz social: el caso de las vendedoras ambulantes mixtecas en Tijuana y el Estado}

A continuación nos apoyamos en la concepción de poder y en las tres consideraciones respecto de la naturaleza del poder de Villarreal (1994 y 2000):

La primera concierne a la cuestión de intencionalidad. El poder se define comúnmente como la capacidad de un individuo de imponer su voluntad sobre otro. Pero es claro que la complejidad de las relaciones de poder reside de manera importante en sus consecuencias no intencionadas, en las redes de rutinas que se disparan o canalizan en diferentes direcciones, no sólo por 
quien ejerce el poder, sino por la circunscripción social que atribuye identidades y roles y responde a estas mismas atribuciones localizándose a sí mismos en un plano inferior, en una condición de subordinación (Villarreal, 2000).

En el caso de interfaz de las vendedoras ambulantes mixtecas y el Estado es interesante observar ciertas consecuencias no intencionadas. Por ejemplo, el agente de Reglamentos no esperaba tal reacción por parte de las mujeres ante su actitud. Sin embargo, ante el trato discriminatorio, ellas arremetieron contra él, excluyéndolo y haciéndole pasar un mal rato frente a sus compañeros de trabajo. Esto es, las mujeres mostraron habilidad para ejercer cierto nivel de poder, asimismo, le mostraron la fuerza del grupo mediante estrategias agresivas tal como él les aplicó.

La segunda consideración es que el poder no es inherente a una posición, un espacio o una persona; no es poseído por ninguno de los actores y no es un proceso suma-cero en el cual su ejercicio por uno de los actores deje a los demás carentes de éste. Las relaciones de poder se generan en interacción y no son totalmente impuestas de un lado (Villarreal, 2000).

Regresamos al caso de interfaz de las vendedoras ambulantes mixtecas y el Estado. Tanto en el mundo académico como en la vida cotidiana, solemos dar por supuesto que los representantes estatales "tienen" el poder. Y ciertamente, el funcionario parecía tener "la sartén por el mango", dado que influye en la autorización de permisos y cuenta con capacidad de ejercer represión, sin embargo, al hacer el análisis de la situación arriba descrita, vemos el uso de técnicas y estrategias de poder por parte de funcionarios, quienes recurren a su estatus institucional, a su género, al acomodo del mobiliario, a gestos, miradas y a la manipulación de atmósferas.

A la vez, se detecta que las mujeres no están desprovistas de poder: las estridentes carcajadas de las mujeres, sus conversaciones en mixteco, las miradas fijas de Leobarda y sus comentarios jocosos constituyen una respuesta que marca su propio estatus en lo que esperan negociar. Las mujeres sólo se someten a los reglamentos hasta cierto punto y también manejan y manipulan sus propias "herramientas y estrategias de poder" para lograr sus fines, de hecho la organización es una de éstas. Al ver las mujeres la reacción del encargado cerraron filas contra él, asimismo, utilizaron la "lengua". Esta 
última, en otros contextos pudiera ser un factor de vulnerabilidad, pero en este caso fue resignificada. No es el uso de la lengua en sí misma, sino que su uso lo apoyan o combinan con la fuerza de la presencia étnica en la ciudad, de los vendedores ambulantes indígenas y de las organizaciones no gubernamentales para utilizarla como instrumento de poder y defensa. Además en ese momento ellas eran mayoría.

La tercera consideración se refiere a "la multidireccionalidad de las relaciones de poder. Sería demasiado simple considerar el poder como procesos unidireccionales donde los objetivos definidos se logran al final. El poder es fluido y materia de negociación: las relaciones de poder se configuran dentro de redes flexibles más que en estructuras fijas" (Villarreal, 2000).

En el análisis del caso de interfaz de las vendedoras ambulantes mixtecas y el Estado podemos ver que hay un espacio de ambigüedad en la relación pues ni el Estado cuenta con el poder absoluto para controlar a las vendedoras o desterrar a las indígenas de la zona turística ni las mujeres pueden llevar a cabo sus actividades libremente como a ellas les interesa. De aquí que surge la necesidad de espacios de negociación. Vimos que en la contienda no hay ganancias de suma cero, es decir, que unos ganen y los otros se queden sin poder; más bien ninguno de los actores logra cumplir completamente sus deseos.

Por ejemplo, aunque al jefe de reglamentos le gustaría evitar la presencia de las mujeres indígenas "que no cuentan con permiso" del andador turístico, le es imposible hacerlo, a lo mucho puede asustarlas y ahuyentarlas por un momento pero no puede evitar su presencia. De igual forma sucedió con las vendedoras: no consiguieron todo lo que deseaban, como más permisos para las trenzeras. Sin embargo, por el momento lograron negociar el restablecimiento del antiguo horario y la cancelación de las multas.

En dichos espacios se ponen en juego elementos subjetivos que tienen que ver con los símbolos y las representaciones sociales, la manipulación de ambientes, los marcos de conocimiento y la redefinición de identidades. Diversos autores han señalado las implicaciones que en términos de poder y bajo ciertos contextos puede tener la distribución de los actores y del mobiliario en los espacios, así como las atmósferas reales o recreadas (Foucaul 1984; Villarreal, 2000).

El segundo escenario transcurre en la oficina del jefe de Reglamentos: en éste se manipula también el ambiente pero de forma diferenciada. Al 
parecer, éste es un espacio menos neutral que la antesala, dado que el espacio y el mobiliario inciden de manera diferencial. Es decir, al no haber una barra de atención al público las miradas del encargado se centran principalmente en Leobarda ante quien hay un reconocimiento de liderazgo y hacia quien casi de manera exclusiva se dirige la negociación. Es así que se da paso a un cambio en el trato, a los movimientos, a las gesticulaciones, miradas y sobre todo a la manipulación del tiempo, eje importante en la creación de atmósferas, transportándose los actores a otra dimensión, donde la estrategia de intimidación es más agresiva, de más contacto visual. Dado el cambio de atmósfera — más agresivo e incisivoellas recurren a otras técnicas de poder, como los gestos, las miradas y las preguntas que demandan respuestas inmediatas.

El jefe de reglamentos tiene como principal función mantener el control del andador turístico y de la presencia indígena que "afea" la zona para los que tienen la capacidad para incidir en la dotación y la extensión de permisos, además de tener la facultad de ejercer un grado de represión para evitar la presencia de quienes no gozan de tales permisos. En cambio, Leobarda, quien representa a algunos grupos de mujeres vendedoras, tiene como objetivo defender a sus paisanas, para lo cual se apoya principalmente en su identidad indígena, capacidad organizativa y alianza con otros grupos de vendedores ambulantes.

En cuanto a la identidad, se observó que las relaciones de poder estuvieron presentes en el proceso, no sólo en forma de coerción directa sino también en que las identidades fueron redefinidas. Una de las etiquetas que se encargan de reproducir las autoridades de la ciudad de Tijuana en torno a las mujeres indígenas es la de Marías, término que en México se asocia a cuestiones étnicas así como a pobreza, ignorancia y sumisión. Además, en el imaginario de algunas autoridades, como lo es el del jefe de la policía de la ciudad, a mujeres que aparecen con sus escobas y sus niños, esto es, asociado al cuidado y la limpieza del hogar. Sin embargo, las mujeres lideradas por Leobarda redefinen la identidad conferida por las autoridades a la de mujeres indígenas comerciantes ambulantes que compiten con los comerciantes establecidos, en su mayoría hombres mestizos, y no sólo eso, sino que además muestran disposición y coraje para defender su espacio de trabajo y negociar frente a frente a la autoridad condiciones laborales como lo es un horario de trabajo y la cancelación de multas. 


\section{Reflexiones finales}

Si bien hay autores para los que el empoderamiento es un concepto occidental con vestigios colonizantes (Mohanty, 2003), el presente trabajo nos nuestra que éste puede ser una herramienta heurística importante y necesaria para entender el porqué algunas mujeres logran modificar sus condiciones de vida y las relaciones de poder así como los obstáculos a los que se enfrentan, y más aún si apoyamos nuestro análisis en herramientas metodológicas cruzadas como lo son la exploración de interfaces, las entrevistas y la observación participante, entre otras.

Como mencionamos anteriormente, los estudios del desarrollo que buscan el empoderamiento de las mujeres conciben éste como un continuum donde la capacitación desempeña un papel esencial, sin embargo, en la realidad se presenta de forma discontinua y fragmentada, mostrando un proceso altamente complejo y resbaladizo en el que convergen otros procesos que podrían mostrar un comportamiento errático.

Lo anterior se debe a que en la vida cotidiana el poder se presenta como un fluido y materia de negociación, en este proceso intervienen aspectos como la multidireccionalidad y la intencionalidad así como la capitalización de recursos sociales, culturales, simbólicos y legales; rejuego y resignificación de éstos que hacen las mujeres así como los diversos actores. Por ejemplo, mientras que el agente de Reglamentos incurre en prácticas de racismo institucional y evitamiento, como señala Taguieff (2001), y trato infantilizante a las mujeres mixtecas para manipular sus demandas, ellas usan como recurso y/o instrumento de poder la lengua indígena y resignifican su identidad logrando negociar algunas de sus demandas.

De aquí que necesariamente tengamos que tomar en cuenta en nuestro análisis, no sólo el dominio de quienes se encuentran en posiciones sociales de ventaja, como en este caso los funcionarios públicos, sino las formas de poder ejercidas por "los de abajo", como en el caso de las vendedoras ambulantes mixtecas y los recursos sociales usados.

Por lo tanto, se advierte la necesidad de una concepción del empoderamiento que permita comprender de manera más clara las relaciones cotidianas de las mujeres en cuestión. Es así que nos inclinamos por una concepción que se apoye en una noción de poder fluida, multidirecional y relacional, esto es, en la que no haya figuras "poderosas" a priori ni ex- 
ternas a las relaciones sociales, ni que las relaciones sean de sometimiento sino que el ejercicio del poder implique ejercerlo y cederlo.

La idea es que el proceso de empoderamiento contemple en sí mismo una concepción de capital social que se genere en las relaciones sociales y se negocie. Lo anterior permitirá desmitificar la idea de que el poder es lineal y visualizar a las mujeres y a los sujetos en situación vulnerable como actores capaces de ejercer poder.

\section{Bibliografía}

Anguiano, José (1997), Los mixtecos en Nuevo León, Nuevo Léon, Consejo para la Cultura de Nuevo León, Desarrollo Integral de la Familia.

Ariza, Marina (2000a), "Género y migración femenina: dimensiones analíticas y desafíos metodológicos”, en Dalia Bassols y Cristina Oehmichen (eds.), Migración y relaciones de género, México, GIMTRAP, Universidad Nacional Autónoma de México.

(2000b), Ya no soy la que dejé atrás. Mujeres migrantes en República Dominicana, México, Instituto de Investigaciones Sociales, Plaza y Valdés.

Arizpe, Lourdes (1988), "La participación de la mujer en el empleo y el desarrollo rural en América Latina y el Caribe: trabajo en síntesis", en J. Aranda (comp.), Las mujeres en el campo, Oaxaca, México, Instituto de Investigaciones Sociológicas, Universidad Autónoma Benito Juárez.

(1975), Indígenas en la ciudad de México: el caso de las "Marias", México, Secretaría de Educación Pública.

Bastos, Santiago (2000), Cultura, pobreza y diferencia étnica en la ciudad de Guatemala, tesis de doctorado, Guadalajara, México, CiESAS, Universidad de Guadalajara.

Batliwala, Srilatha (1993), Empoderamiento de las mujeres en Asia del Sur. Conceptos y prácticas, Departamento de Educación de Adultos del Pacífico Asiático del Sur, y por la campaña Liberación del Hombre/Acción para el desarrollo de la FAO.

Braunstein, Néstor (2001), "México: en psicoanálisis", Debate Feminista, año 2, vol. 24. Camus, Manuela (2000), Ser indígena en ciudad de Guatemala, tesis de doctorado, Guadalajara, México, Centro de Investigación y Estudios Superiores en Antropología Social.

Canabal, Beatriz (1997), "Mujeres en el movimiento campesino", en Dalia Barrera Bassols, Participación política de las mujeres y gobiernos locales en México, México, GIMTRAP.

Clark, Víctor (1996), "Los mixtecos en la frontera (Baja California)", Cuadernos de Ciencias Sociales, vol. 10, serie 4. 
Comaroff, John y Jean Comaroff (1992), "Of Ethnicity and Totemism”, Theory, Ethnography, Historiography, San Francisco, Oxford, Westvies Press Boulder.

Conway, Jill, Susan C. Bourque y Joan W. Scott (1997), "El concepto de género". en Marta Lamas (comp.), El género: la construcción social de la diferencia sexual, México, PuEg, Universidad Nacional Autónoma de México.

Dahl, Robert (1957), “The Concept of Power”, Behavioural, núm. 2.

Foucaul, Michel (1984), Un diálogo sobre el poder, España, Alianza.

Frías, Sonia (2007), "Diferencias regionales en violencia doméstica en México: el rol de la estructura patriarcal”, en Roberto Castro e Irene Casique (eds.), Estudios sobre cultura, género y violencia contra las mujeres, Cuernavaca, Mor., Centro Regional de Investigaciones Multidisciplinarias, Universidad Nacional Autónoma de México.

Gall, Olivia (2002), "Estado federal y grupos de poder regionales frente al indigenismo, el mestizaje y el discurso multiculturalista: pasado y presente del racismo en México”, Debate Feminista, año 12, vol. 24.

Gayle, Rubin (1997), "Notas sobre la economía política del sexo”, en Marta Lamas (comp.), El género: la construcción social de la diferencia sexual, México, PuEG, Universidad Nacional Autónoma de México.

Hernández, Aída (2001), La otra frontera. Identidades múltiples en el Chiapas poscolonial, México, ciesas.

Instituto Nacional de Estadística, Geografía e Informática (2010), Censo de Población y Vivienda 2010, México, INEGI.

— (2000), XII Censo General de Población y Vivienda, México, Inegi. (1980), X Censo General de Población y Vivienda, México, InEgi.

Lagarde, Marcela (1996), “El género, fragmento literal: la perspectiva de género”, en Género y Feminismo. Desarrollo humano y democracia, España, Horas y Horas.

Lamas, Marta (1986), El género: la construcción cultural de la diferencia sexual, México, PUEG, Universidad Nacional Autónoma de México.

Latour, Bruno (1986), “The Powers of Association”, en J. Law (edit.), Power, Action and Belief: A New Sociology of Knowledge, Londres, Routledge.

León, Magdalena (1997), "Empoderamiento en la teoría y práctica del feminismo", en Magdalena León (comp.), Poder y empoderamiento de las mujeres, Santa Fe de Bogotá, Tм Editores, Tercer Mundo, Facultad de Ciencias Humanas.

Lestage, Françoise (1999), "Mujeres bajo influencia. El peso de los familiares y conocidos sobre la salud femenina", en N. Ojeda (dir.), Género, familia y conceptualización social de la salud reproductiva en México: el caso de las mujeres de la población abierta de Tijuana, Tijuana, El Colegio de la Frontera Norte.

Long, Norman (2001), "Networks Social Capital and Multiple Family Enterprise: Local to Global”, en N. Long, Development Sociology. Actor Perspectives, Londres y Nueva York, Routledge, Taylor and Francis Group. 
Martínez, Regina y Guillermo de la Peña (2004), "Migrantes y comunidades rurales: resignificación, etnicidad y redes sociales en Guadalajara", Revista de Antropología Social, t. v, núm. 13, España.

— (2007), Vivir invisibles: la resignificación cultural entre los otomíes urbanos de Guadalajara, México, CiEsAs.

Mohanty, Chandra (2003), Feminism without Borders: Decolonizing Theory, Practicing Solidarity, Durham, Duke University Press.

Morokvásic, Mirjana (1983), "Women in Migration: Beyond the Reductionist Outlook", en Annie Phizacklea (eds.), One -way Ticket: Migration and Female Labor, Londres, Routledge,.

Niño, Lya (2009), Vicisitudes del capital social. Procesos de empoderamiento de las mujeres indígenas inmigrantes a Tijuana y San Quintín, México, Universidad Autónoma de Baja California.

Nolasco, Margarita (1995), Migración indígena en las fronteras nacionales, México, Centro de Ecología y Desarrollo.

Oehmichen, Cristina. (2000), "Las mujeres indígenas migrantes en la comunidad extraterritorial", en Dalia Barrera Bassols y Cristina Oehmichen (eds.), Migración y relaciones de género en México, México, Universidad Nacional Autónoma de México, gimTrap.

Ortner, Sherry y Harriet Whitehead (1997), "Acerca de los significados sexuales", en Marta Lamas (comp.), El género: la construcción social de la diferencia sexual, México, Pueg, Universidad Nacional Autónoma de México.

Portes, Alejandro (1998), "Social Capital: Its Origins and Applications in Modern Sociology", Annual Review of Sociology, núm. 22.

Scott, Joan (1986), "El género: una categoría útil para el análisis histórico", en Marta Lamas (comp.), El género: la construcción social de la diferencia sexual, México, PUeg, UnAm.

Stromquist, Nelly (1997), "La búsqueda del empoderamiento: en qué puede contribuir el campo de la educación”, en Magdalena León (comp.), Poder y empoderamiento de las mujeres, Santa Fe de Bogotá, Colombia, тм Editores, Tercer Mundo, Facultad de Ciencias Humanas de Bogotá.

Szasz, Ivonne (1994), "Migración y relaciones sociales de género: aportes de la perspectiva antropológica”, en Estudios Demográficos y Urbanos, vol. 9, núm. 1, enero-abril, pp. 129-150.

Taguieff, Pierre (2001), "El racismo”, Debate Feminista, año 12, vol. 24. pp. 3-14.

Van Den Berghe, Pierre (1971), Problema raciales, México, Fondo de Cultura Económica.

Velasco, Laura (1995), "Migración femenina y estrategias de sobrevivencia de la unidad doméstica: un caso de estudio de mujeres mixtecas en Tijuana", en S. González (comp.), Mujeres, migración y maquila en la frontera norte, México, El Colegio de México, El Colegio de la Frontera Norte. 
(2000), "Imágenes de violencia desde la frontera México-Estados Unidos: migración indígena y trabajo agrícola”, El Cotidiano, vol. 16, núm. 101, pp. 92-102.

(1996), "La conquista de la frontera norte: vendedoras ambulantes indígenas en Tijuana”, en L. Velasco y E. Lazos, Estudiar a la familia. Comprender a la sociedad, México, Pueg, Desarrollo Integral de la Familia, Consejo Nacional de Población, unicef, Universidad Autónoma de México.

Villarreal, Magdalena (s/f), "Pautas metodológicas para el análisis de las interfaces sociales".

— (2001), "Puercos, gallinas, ovejas, vacas... y maridos: la naturaleza del capital en las microempresas de mujeres campesinas", ponencia, xxi Seminario de Economía Agrícola del Tercer Mundo, México, Universidad Nacional Autónoma de México, 3 de octubre de 2001.

- (2000), "La reinvención de las mujeres y el poder en los procesos de desarrollo rural planeado”, La Ventana, vol. 2, núm. 2.

(1994), Wielding and Yielding: Power, Subordination and Gender Identity in the Context of Mexican Development Project, tesis de doctorado, Holanda, Wageningen University.

Weber, Max (1946), Essays in Sociology, Oxford, Oxford University Press.

Woo, Ofelia (2001), Las mujeres también nos vamos al norte, Guadalajara, Universidad de Guadalajara.

Artículo recibido el 23 de enero de 2012. Segunda versión aprobada el 11 de marzo de 2013. 